\title{
The Call of the proper nouns in the Quran (Rhetorical Study)
}

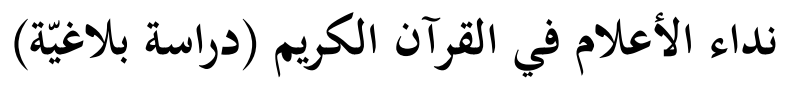

\begin{abstract}
Abdelrahman Moawad Ali Tahawi
mhassan20_1@yahoo.com

Sultan Abdul Halim Mu'adzam Shah International Islamic University

Malaysia
\end{abstract}

• Received: 29.08.2021 • Accepted: 18.10.2021 • Published online: 25.11 .2021

Abstract: This research contains three objectives, the first of which is to extrapolate the positions of the call of the flags that are mentioned in the Qur'anic verses and to form a clear picture of this type of call with the analysis of a number of Qur'anic evidence rhetorically. The second is to follow what the rhetoricians dealt with regarding directing the discourse in the style of the appeal, and the use of the forms of the appeal in a way other than its original meaning. The third is to monitor the overall relationship between the question and the Qur'anic call and the significance of this relationship. In writing this research, the researcher followed the inductive and analytical approaches by extrapolating and tracing the texts and then analyzing them rhetorically. The research concluded with several results, including: (1) The Noble Qur'an has numerous references to the call to science, therefore it is an honor for the herald in some cases and a mocking in others. (2) In many places, the Qur'anic verses adopted the method of calling, which is one of the methods of preparation and educational preparation that leads to attracting the caller's attention and urging him to approach and focus, as well as creating a sense of familiarity, grooming, and privacy that makes him feel how important it is, and the interest of the Qur'anic discourse in it makes him more ready to receive and comply. (3) The frequent occurrence of command, prohibition, and interrogation construction methods associated with the Qur'anic call, as well as their occurrence in the Holy text, is frequently accompanied by a semantic shift in which these methods separate their direct literal significance from other indications, which is known in the old rhetorical lesson as the idea of purposes. This change from literal to rhetorical meaning implies a unique capacity that 
aids in drawing the recipient's attention and maintaining his communication with the text at its most responsive and interactive level.

Keywords: The proper noun, the Qur'an, Arabic Rhetorical, significance

الملخص: يحتوي هذا البحث على ثلاثة أهداف، أولها استقراء مواضع نداء الأعلام التي وردت في السور القرآنية وتكوين صورة واضحة لهذا النمط من أنماط النداء مع تحليل عدد من الشواهد القرآنية تحليلا بلاغيا. ثانيها تتبع ما تناوله البلاغيون بشأن توجيه الخطاب في أسلوبه النهاب النداء،

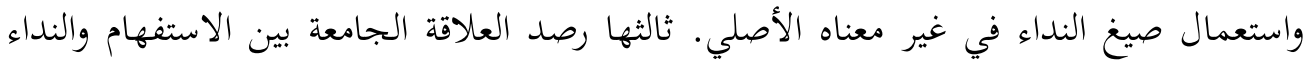
القرآني ومعزى هذه العلاقة. واتبع الباحث في كتابة هذا البحث المنهجين الاستقرائي والتحليلي وذلك باستقراء وتتبع النصوص ثم تحليلها بلاغيا. وقد خلص البحث إلى عدة نتائج منها: (1) تتعدد دلالات النداء بالعلمية في القرآن الكريم فتكون في بعض الشواهد تشريفا للمنادى وتكون سخرية منه في بعضها الآخر.(2) اعتمدت السور القرآنية أسلوب النداء في مواضع كثيرة وهو أحد أساليب التوطئة والتهيئة التربوية التي تؤدي إلى جذب انتباه المنادي وحثه على الاقتراب والتركيز وإيجاد نوع من الألفة والاستمالة والخصوصية التي تشعره بمدى أهميته واهتمام الخطاب القرآني به يجعله أكثر استعدادا للتلقي والامتثال. (3) كثرة ورود الأساليب الإنشائية من أمر ونهي واستفهام مقترنة مع النداء القرآني وكثيراً ما يكون ورودها في النص الكريم مصحوبا بتحول دلالي تفارق فيه هذه الأساليب

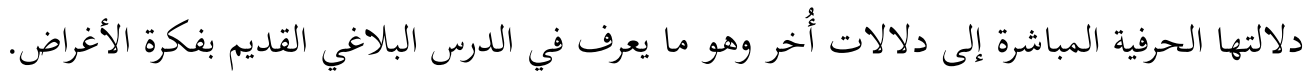

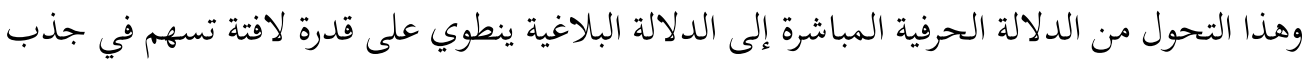
انتباه المتلقي وبقاء تواصله مع النص في أكثر حالاته تجاوبا وتفاعلا. كلمات دلالية: الأعلام، القرآن، الخطاب، الدلالة

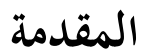

لما كان القرآن الكريم يرجع في أحد جوانب إعجازه إلى بيانه وأدبه، وبلاغته وفصاحته، وأسلوبه ونظمه فإن الحاجة في هذا العصر الذي يتسم بالتنكر لحقائق الإيمان، والتمرد على فيلى سلطان الدين تصبح ماسة إلى ما يساعد على جلاء تلك المعجزة ، وتقريبها إلى الأفهام. 
Abdelrahman Moawad Ali Tahawi

من هنا كان اختياري لهذا الموضوع "نداء الأعلام في القرآن الكريم، دراسة بلاغية ـ وترجع أهمية هذه الدراسة إلى (1) اتصاله بأعظم نص لغوي وهو القرآن الكريم. (2) اهتمامه بدراسة جانب مهم يسهم بقدر كبير في فهم معاني القرآن الكريم وتدبر أحكامه. (3) إبراز الجانب الدلالي لنمط من أنماط أساليب النداء في القرآن الكريم. بهريم. منهج البحث

إن المنهج المتبع في تناول هذا البحث يقوم على الاستقراء والوصف والتحليل على أساس من الأخذ المتكافئ والربط التام.

\section{نتائج الدراسة وتحليلها}

المبحث الأول: ما كان النداء فيه من جهة الله

يتجلى للمتأمل في النظم القرآني كيف يكون النداء بالعلمية في بعض الشواهد تشريفًا للمُنادَى

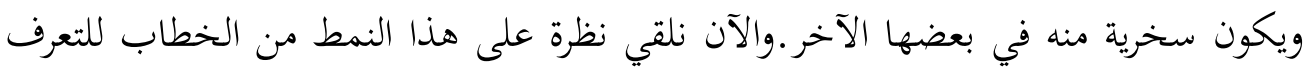
على الدلالة البلاغية له من خلال تحليل عدد من الشواهد القرآنية.

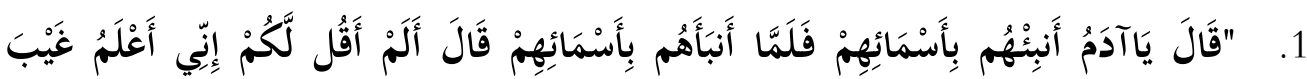

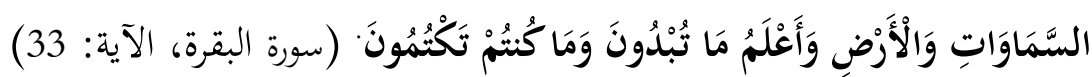
جاء افتتاح الخطاب بالنداء - مع أن المُنادَى غير بعيد عن سماع الأمر الإلهي -

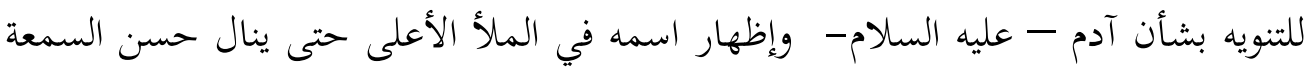

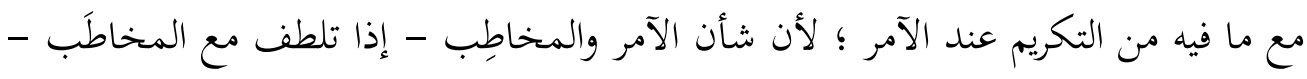
أن يذكر اسمه ولا يقتصر على ضمير الخطاب قال الألوسي: والسر في إيجاد آدم ، ولم يقل

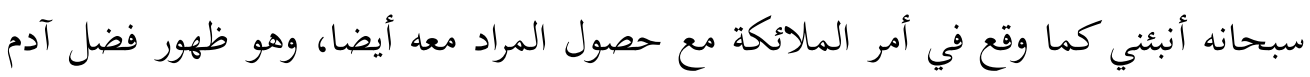
إبانة لما بين الرتبتين من التفاوت". (Al-Alūsī, 2008:1/242) "واسم آدم من الأديم وهو جلدة الأرض التي منها جسمه ، وحظ ما فيه من أديم الأرض هو اسمه الذي أنبأ عنه لفظ آدم ، الأسماء" (Al-Alūsì, 2008) 
Abdelrahman Moawad Ali Tahawi

وقوله :" أَنَبَأهُم بِأَسْمَائِهم "أي أخبرهم بمسميات الأشياء فالمقصود بالأسماء " أسماء المسميات" ، فحذف المضاف إليه لكونه معلوما مدلولا عليه بذكر الأسماء; وقد أشار الزمخشرى إلى هذا بقوله :"فإن قلت: هلا زعمت أنه حذف المضاف وأقيم المضاف إليه مقامه، وأن الأصل: وعلم آدم مسميات الأسماء؟ قلت: لأن التعليم وجب تعليقه بالأسماء لا بالمسميات، لقوله: أنبئوني بأسماء هؤلاء ، أنبئهم بأسمائهم فلما أنبأهم بأسمائهم فكما علق الإنباء بالأسماء لا بالمسميات ولم يقل: أنبئوني بهؤلاء، وأنبئهم بهم، وجب تعليم بليق التعليم (Al-Zamahnšarī, 1995: 1/253)."بها

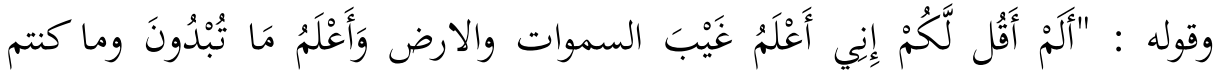
تكتمون" استفهام إنكاري وتعريض بالمالائكة حيث بادروا بالسؤال عن الحكمة ، وكان الأولى الى ولى أن يأخذوا بالأدب المناسب لمقام الألوهية ، فيتركوا السؤال عنها إلى أن يستبين لهم أمرها بوجه من وجوه العلم. ، وفي الكلام التفات، فمقتضى السياق أن يقال: وتكتمون ........"إلخ وبالإضافة إلى فوائد الالنفات من جذب انتباه السامع ، وشحذ ذهنه ،ودفع الملل عنه، فإن

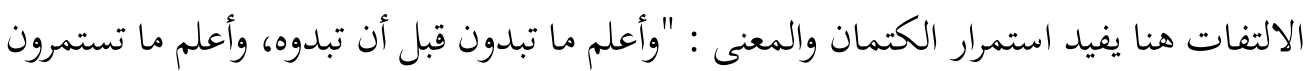

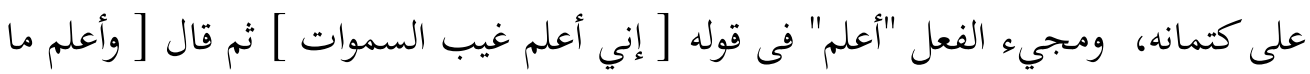
تبدون ] للاهتمام بالخبر والتنبيه على إحاطة علمه تعالى بجميع الأشياء.

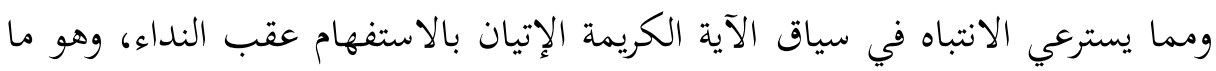
يستلزم الوقوف عنده والبحث في دلالاته. ويجدر بنا أن نشير هنا أولا إلى أنه مع كثرة (النداء) في الكلام، فهو ليس مقصوداً بالذات، بل هو لتنبيه المخاطب ليصغي إلى ما يجيء بعده

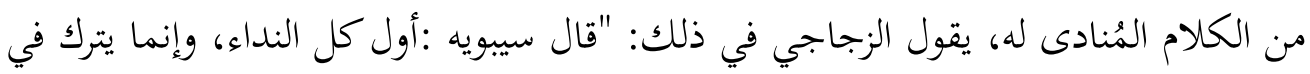
بعضه تخفيفا، وذلك أن سبيل المتكلم أن ينادي من يخاطبه ليقبل عليه، ثم يُخاطبه مُخبراً

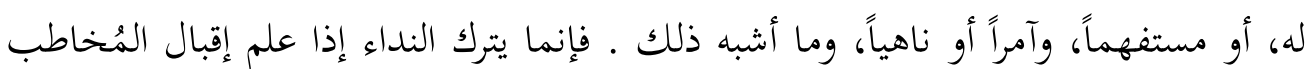
على المتكلم استغناءُ بذلك".(Al-Zuğāğīî, 1985:111-112) 
Abdelrahman Moawad Ali Tahawi

ولكي نرصد هذه العلاقة الجامعة بين الاستفهام والنداء القرآني نعرض هنا بعض اللمحات الدلالية لأسلوب الاستفهام.

يعد أسلوب الاستفهام أحد أساليب الإنشاء الطلبي في الجملة العربية سواء كان لهدف لهان محدد ومباشر، أم كان لتصور إيحائي غير مباشر عند المتكلم، فالاستفهام قد لا يبحث فيه المتكلم عن إجابة محددة، وإنما يهدف إلى تصور ما يتحدث عنه فيخرجه عن حقيقته إلى لى

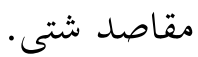
ولا مراء في أن أسلوب الاستفهام أسلوب لغوي - قبل كل شيء - وأساسه طلب

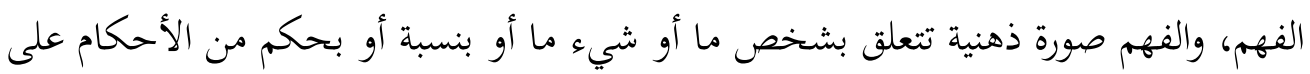
جهة اليقين والظن؛ ولذا فإن الاستفهام يعد ذا علاقة وثيقة بالرغبة في " المعرفة " التي تزيل

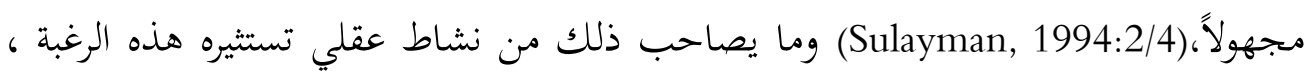
ومن هنا يتضح أن الاستفهام له قدرة ذاتية على جذب انتباه المتلقي. " إنك في الاستفهام تطلب ما هو في الخارج ليحصل في ذهنك نقش له مطابق، فنقش الذهن في الأول تابع ، وفي الثاني متبوع". (Al-Sakākī, 1987:146) إن عدم المعرفة حافز مثير للذهن تنبعث منه حيوية الذهن في التلقي وهذه الحيوية -

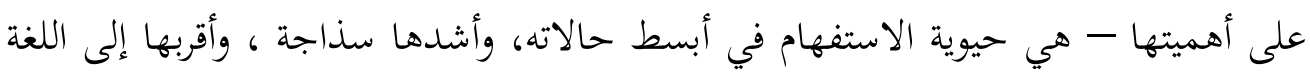

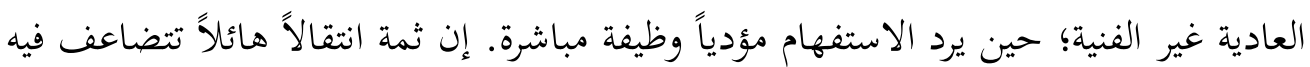

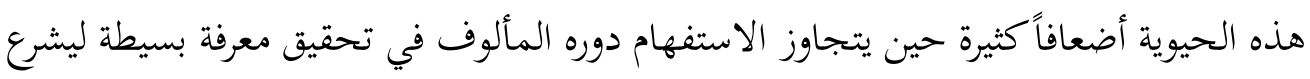
في اكتساب دلالة جديدة ينضاف فيها بُعْد شعوري وظل دلالي إلى الاستفهام البسيط ـ. وهذا ما يتبلور فيما يسمى بالغرض البلاغي.(Murād, 2004:340)

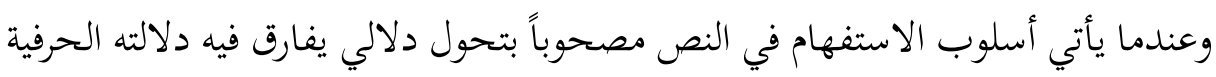
المباشرة إلى الدلالة البلاغية مع اقترانه بالنداء فإننا نجد أن هذا التحول مع الاقتران بالنداء ينطوي على قدرة لافتة على جذب انتباه المتلقي ، وبقاء تواصله مع النص في أكثر حالاته

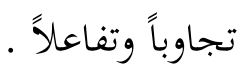


Abdelrahman Moawad Ali Tahawi

وقد يرد أسلوب الاستفهام دالاً على الإنكار-كما في موضع الشاهد- فإذا به يلتقي

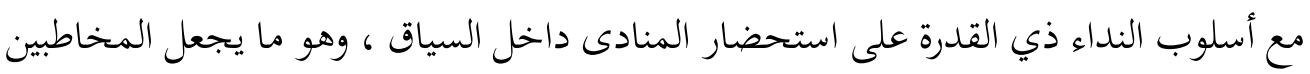

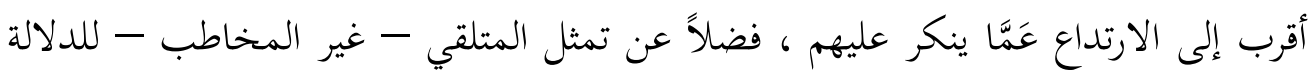

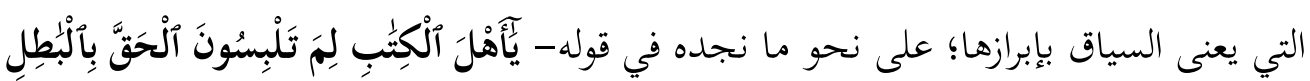

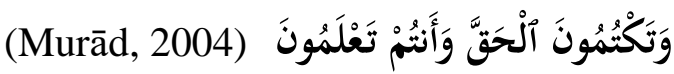

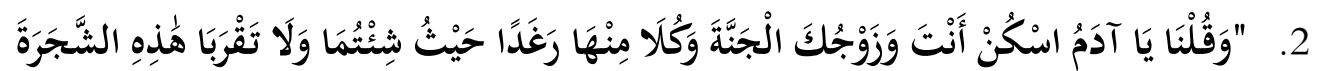

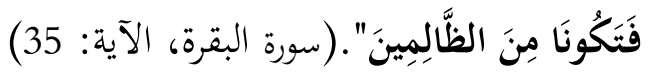

الخطاب في الآية خطاب تشريف حيث جاء افتتاح الخطاب بنداء آدم تنويها بفضله وكرامته،"ونداء آدم قبل تخويله سكنى الجنة نداء تنويه بذكر اسمه بين الملأ الأعلى لأن نداءه

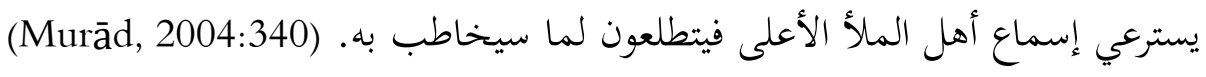

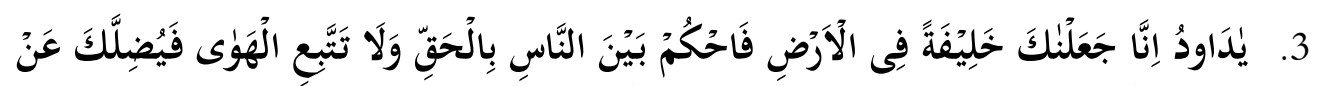

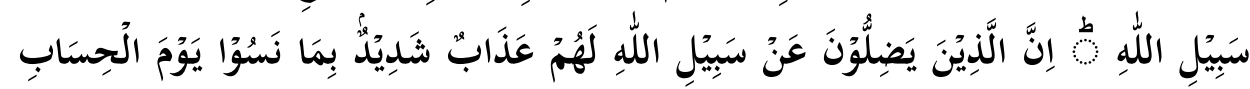

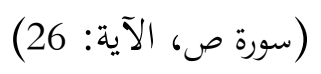

جاء افتتاح الخطاب بالنداء لاسترعاء وعي المنادى واهتمامه بما سيقال له. والخليفة:

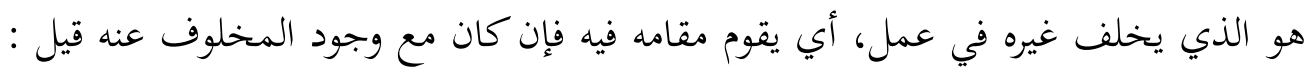
هو خليفة فلان، وإن كان بعد ما مضى المخلوف قيل: هو خليفة من فلان والمراد هنا المعنى

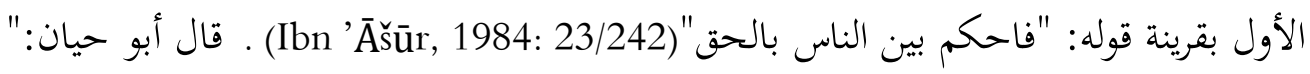

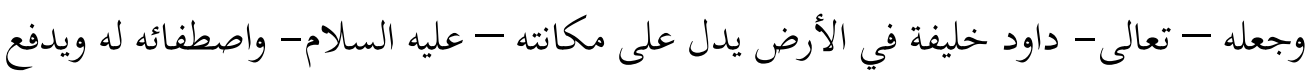

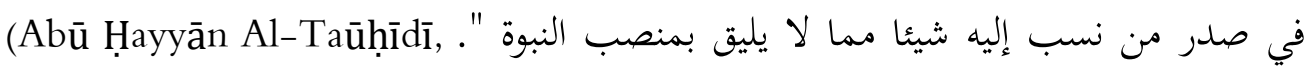
1983: 7/395) 
وقوله : "فَاحُكُمْ بَيْنَ النَّاسِ بِالْحَقِّ"، أي احكم بينهم بالعدل. قال في البحر " أن هذا أمر

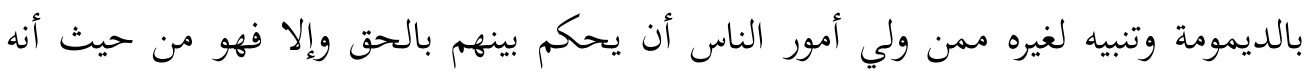

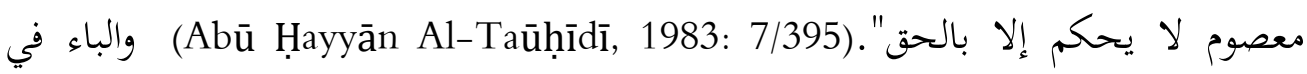

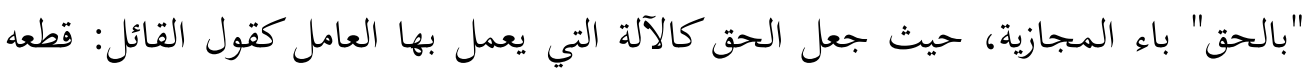
بالسكين، وضربه بالعصا.

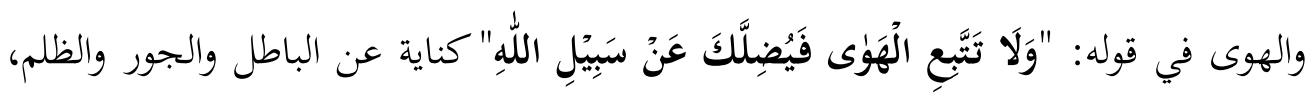

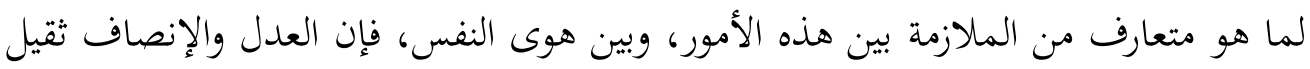

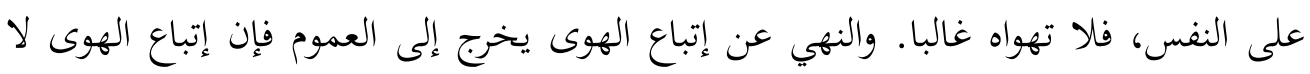

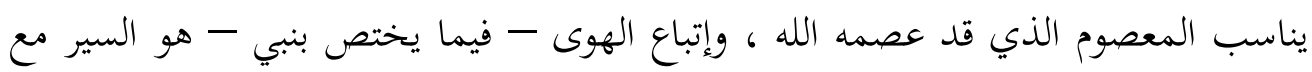
الانفعال الأول، وعدم التريث والتثبت والتبين ـ والفاء في: "فيضلك" هي فاء التهاء السببية، فالسياق يشير إلى أن إتباع الهوى يكون سببا للضلال.

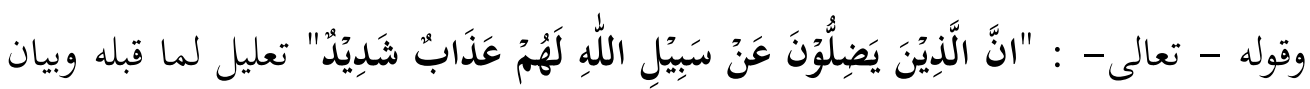

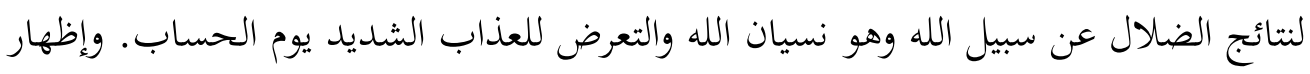

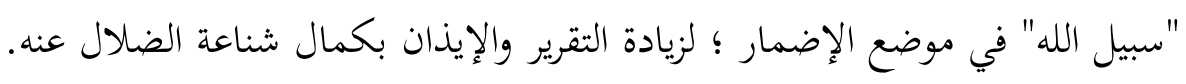

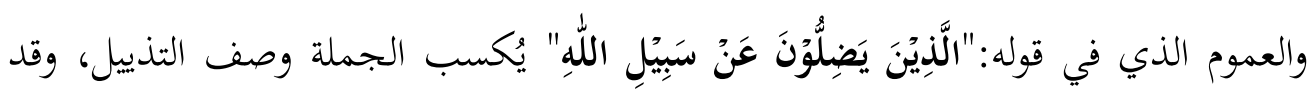

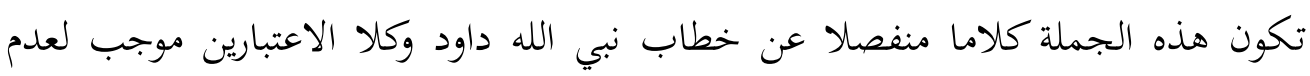

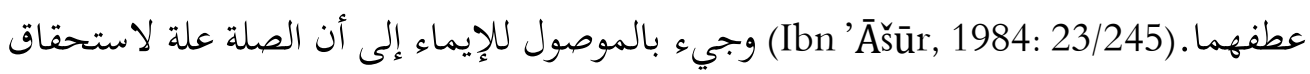

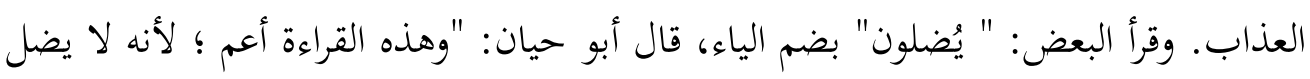

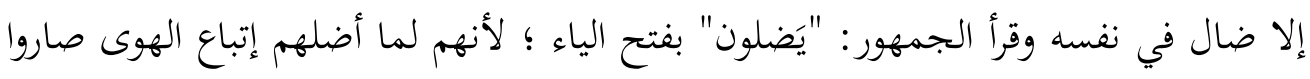

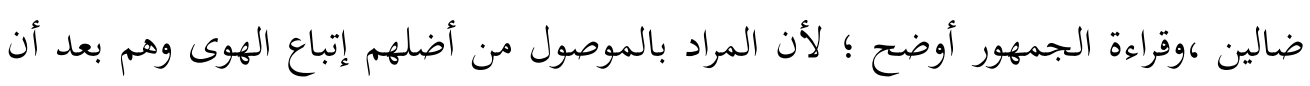

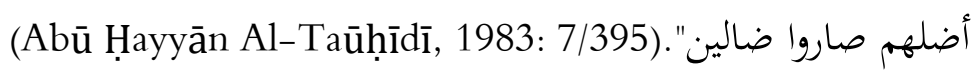


Abdelrahman Moawad Ali Tahawi

والباء في قوله- تعالى - : "بِمَا نَسُوُا يَوُمَ الُحِسَابِ"سبية، أي بسبب نسيانهم يوم الحساب، فهو تعليل لثبوت العذاب الشديد لهم. وفي جعل الضلال عن سبيل الله ونسيان يوم الحساب سببين لاستحقاق العذاب الشديد تنبيه على تلازمهما فإن الضلال عن سبيل الله يفضي إلى الإعراض عن مراقبة الجزاء.

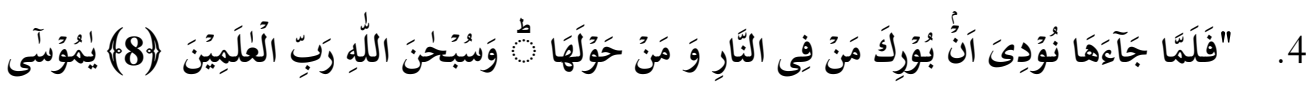

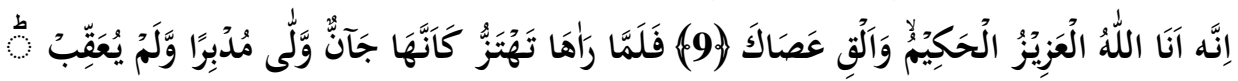

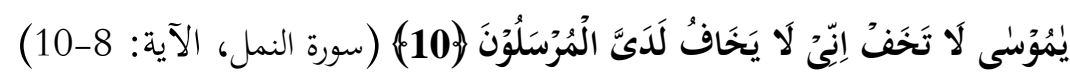
جاء الخطاب لموسى -عليه السلام- في هذا الموقف وهو في طريق عودته من أرض مدين إلى مصر وقد ضل طريقه في ليلة مظلمة باردة يدل على هذا قوله لأهله: "سَأتِيُكُمْ مِنْهَها

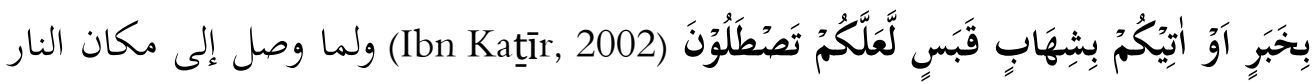
رأى منظراً هائلاً حيث رأى النار تضطرم في شجرة خضراء ، ولا تزداد النار إلا توقداً، ولا تزداد إلا خضرة ونضرة، ثم رفع رأسه فإذا نورها متصل بعنان السماء قال ابن عباس:" لم تكن ناراً وإنما كانت نوراً يتوهج". (Abū Hayyān Al-Taūhīdī, 1983:7/55) وقف موسى عندئذ متعجباً مما رأى وجاءه النداء العلوي:" نُودِيَ أَنْ بُورِكَ مَنْ فِي النَّارِ وَمَنْ حَوْلَهَا"، أي نودي من جانب الطور بأن بوركت يا موسى وبورك من حولك، وهم الملائكة الذين وكل إليهم إنارة المكان وتقديسه، و "بُورك" من البركة، وهي زيادة الخير والنماء. قال الثعلبي: العرب تقول باركك الله، وبارك فيك وبارك عليك ، وبارك لك، أربع لغات فبوركتَ مولوداً وبوركت ناشئا وبوركت عند الشيب إذ أنت أشيب (Abū Hayyān Al-Taūhị̄īe 1983:7/55)

وقوله :" مَنْ فِي النَّارِ" المراد به موسى، فإنه لما حل في موضع النور صار محيطا به، ولم يُذكر موسى هنا باسمه العلم أو بضمير الخطاب؛ لأن في معنى صلة الموصول إيناسًا له وتلطفا، كقول النبي- صلى الله عليه وسلم- لعلي بن أبي طالب: "قم أبا تراب" فهو من 
Abdelrahman Moawad Ali Tahawi

التلطف الذي يذكر فيه بعض ما التبس المتلطف به من أحواله وهذا الكالام فيه بشارة لموسى - عليه السلام- ببركة النبوة. قال في البحر : وبدؤه بالنداء تبشير لموسى وتأنيس له ومقدمه لمناجاته، وجدير أن يبارك من في النار ومن حواليها إذ قد حدث أمر عظيم وهو تكليم الله (Abū Hayyān Al-Taūhīdī, 1983: 7/56) (لموسى وتنبيئه"

وقوله : "وَسُبْحَنَ اللَهِ رَبِّ الُحلَمِيْنَ" أي تقدس - وتنزّه رب العزة العلي الشأن ، الذي لا يشبهه شيء من مخلوقاته لا في ذاته ، ولا في صفاته ولا في أفعاله.

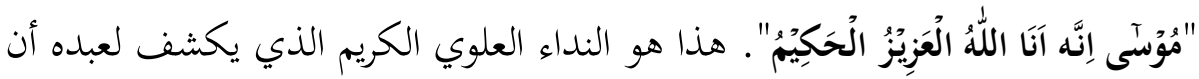
الذي يناديه هو الله العزيز الحكيم ، وقد كان هذا النداء للاصطفاء ، ووراء الاصطفاء التكليف بحمل الرسالة إلى أكبر الطغاة في الأرض في ذلك الحين، ومن ثم جعل ربه يعده ويجهزه ويقويه.

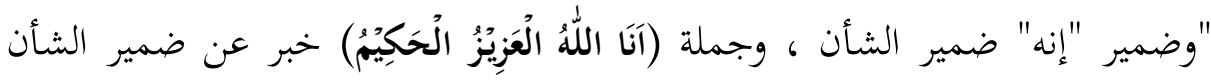
والمعنى: إعلامه بأن أمرا مهما يجب عليه وهو أن الله عزيز حكيم ، أي لا يغلبه شيء". (Ibn 'Āšūr, 1984:19/227)

وتقديم هذا القول بين يدي ما سيلقى إليه من الأمر، لإحداث رباطة جأث لموسى ليعلم أنه أصطفي للنبوة، وليعلم أنه سيتعرض إلى أذى ، وذلك كناية عن كونه سيصير رسولاً، وأن الله يؤيده وينصره على كل قوي، وليعلم أن ما شاهده ليس بعجيب في جانب حكمة الله فلذلك أتبع هذا بقوله: "وَأَلْقِ عَصَاكَ " وفَى هذا إيجاز بالحذف، فحذفت جملة: فألقاها فانقلبت إلى حية، وذلك لدلالة السياق عليه وقد ذكر هنا أمر العصا باختصار حيث لم يذكر السياق الحوار الذي جاء في سورة طه ؛ لأن العبرة المطلوبة هنا هي عبرة النداء والتكليف.

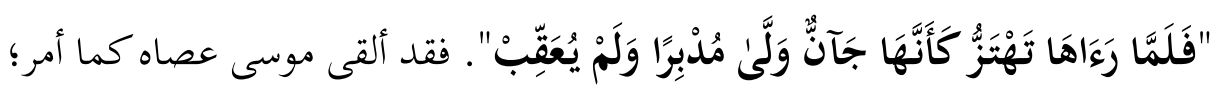
فإذا هي تدب وتسعى وتتحرك حركة سريعة كحركة ذلك النوع السريع من الحيات، و "الجان" هو جنس من الحيات (Ibn Al-Turkmān̄̄, 2020:267) وهو شديد الاهتزاز، وهنا أخذت 
Abdelrahman Moawad Ali Tahawi

موسى المفاجأة التي لم تخطر له ببال ، وجرى بعيدا عن الحية، ثم نودي موسى بالنداء العلوي المطمئن؛ وأعلن له عن طبيعة التكليف الذي سيلقاه:

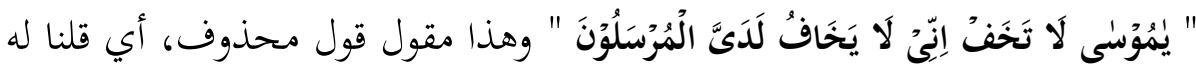
لا تخف والنهي عن الخوف مستعمل في النهي عن استمرار الخوف؛ لأن خوفه قد حصل.

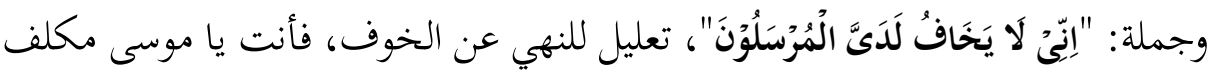
بالرسالة والرسل لا يخافون في حضرة ربهم وهم يتلقون التكليف وفي هذا إشارة إلى تشريفه

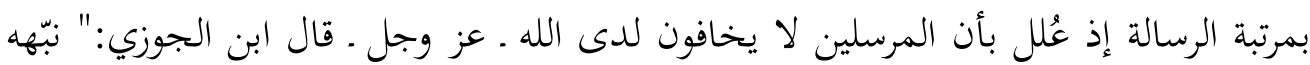

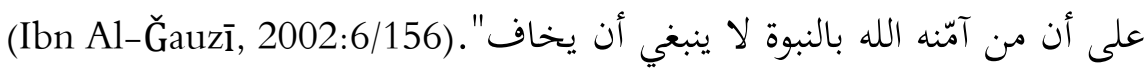

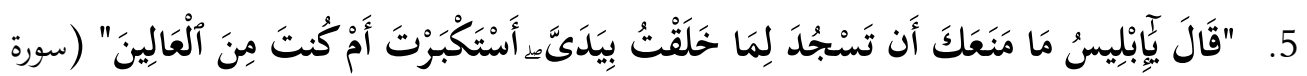

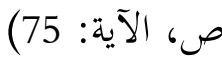

لما ذكر الله - تعالى - مآل السعداء المتقين، ثنَّى بذكر حال الأشقياء المجرمين، ثم ذكر بعض الأدلة على صدق رسالة محمد - صلى الله عليه وسلم- ، وختم السورة الكريمة بذكر قصة آدم وإبليس، وامتناعه عن السجود لآدم تحذيرا للبشر من عدوهم الأكبر ومن رسن وساوسه وإغوائه. (Al-Ṣābūnī, 1997:3/62)

والخطاب في الآية الكريمة هو خطاب توبيخ، وقيل إن الخطاب حينئذ كان بواسطة ملك من الملائكة؛ لأن إبليس لما استكبر قد انسلخ عن صفة الملكية، فلم يعد أهلا لتلقي الخطاب من الله عز وجل، ومعنى الخطاب، أي قال له ربه ما الذي صرفك يا إبليس عن عن صن

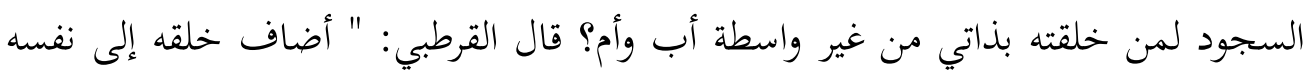
تكريما لآدم، وإن كان خالق كل شيء."Al-Qurțubī, 2006) والتثنية في: "يدي" لإبراز كمال الاعتناء بخلق آدم والذي يستدعي إجلاله وإعظامه وفي هذا تأكيد للإنكار والتوبيخ،

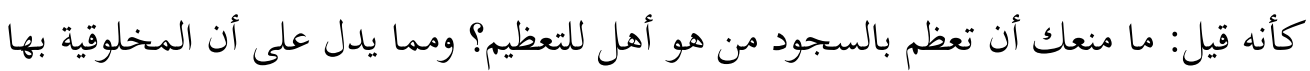
وصف تعظيم قول موسى لآدم: " أنت آدم الذي خلقك من الله - تعالى - بيده" (Imām Al) 
Abdelrahman Moawad Ali Tahawi

(Buhāāī, 1990: 6614، وأخرج ابن جرير والبيهقي عن ابن عمر رضي الله عنهما قال: خلق

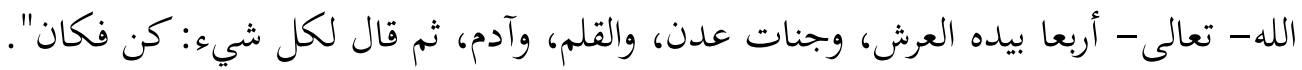
وقوله تعالى : "أَسْنَكْبَرْتَ أَمْ كُنتَ مِنَ أْلْعَالِيَ"، أي أستكبرت الآن عن السجود أَم كنت قديما من المتكبرين على ربك؟ وقد حاء هذا السؤال على جهة التوبيخ لإبليس لاستنكافه عن السجود، قال في التسهيل: " وقال القاضي أبو بكر بن الطيب : دخلت همزة الاستفهام على رلى ألف الوصل فحذفت ألف الوصل، وأم هنا معادلة ، والمعنى أستكبرت الآن أم كنت قديما (Al-Kalabī, 1995:579). ممن يعلو ويستكبر المبحث الثاني: ما كان النداء فيه من جهة الخلق نستعرض في هذا المبحث نمطا آخر من أنماط نداء الأعلام وهو النداء الصادر من الخلق ودلالثه؛ حيث يأتي نداء المخاطبين لقصد توبيخهم بسبب تفريط صادر عنهم أو بسبب إعراضهم عن الإيمان بالحق الذي استيقنته أنفسهم. وفيما يلي تحليل لبعض شواهد

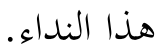

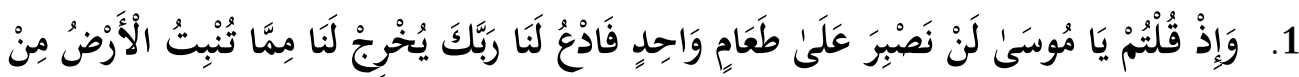

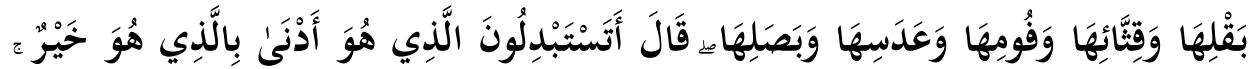

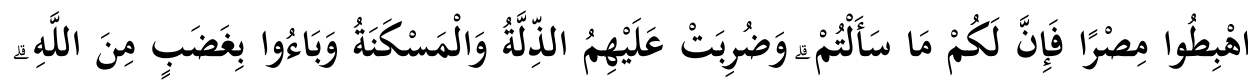

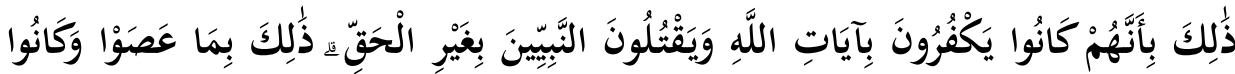

$$
\text { يَعْتَدُونَ (سورة البقرة، الآية: 61) }
$$

لما امتن عليهم بهذه النعمة العظيمة من أكل المن والسلوى وشرب هذا الماء الرباني

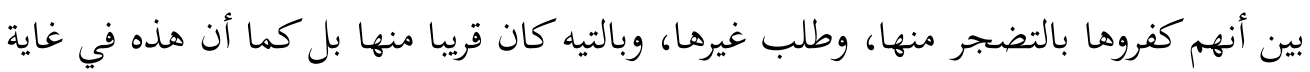
العلو كان مطلوبهم في غاية الدناءة والسفول فقال تعالى وإذ قلتم أي بعد هذه النعم كلها يا تهريا موسى منادين له باسمه من غير تعظيم. (Al-Baqā'î̀, 1984:1/414) 
Abdelrahman Moawad Ali Tahawi

قال الرمخشري :"كانوا فلاحة فنزعوا إلى عكرهم فأجموا ما كانوا فيه من النعمة وطلبت أنفسهم الشقاء" (Al-Zamaȟšarī, 2009:1/314) هذا عن مناسبة الآية الكريمة وارتباطها بالسياق القرآني أما عن نظمها ودلالة هذا النظم فنجد ما يلي:

جملة "وََإذْ قُلْتُمْ يَا مُوسَنْ لَنْ نَصْبرَرِ" معطوفة على الجمل قبلها وورود العطف هنا يفيد ربط الجملة بما قبلها من الآيات التى جاءت في سياق الحديث عن تعداد النعم على بني

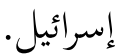

والتعبير بـ" لن" المفيدة لتأبيد النفي لأداء معنى كلامهم المحكي هنا في شدة الضجر

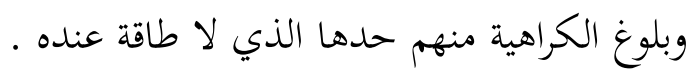
ووصفوا الطعام بواحد وإن كان هو شيئين المن والسلوى لأن المراد أنه متكرر كل يوم

وجملة يخرج لنا إلى آخرها هي مضمون ما طلبوا منه أن يدعو به فهي في معنى مقول

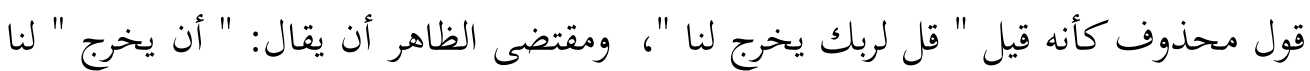
فعدل عن ذلك إلى الإتيان بفعل مجزوم في صورة جواب طلبهم إيماء إلى أنهم واثقون بأنه إن دعا ربه أجابه حتى كأن إخراج ما تنبت الأرض يحصل بمجرد دعاء موسى ربه، وهذا لهاء أسلوب تكرر في القرآن مثل قوله قل لعبادي الذين آمنوا يقيموا الصلاة وقل لعبادي يقولوا التي هي أحسن وهو كثير فهو بمنزلة شرط وجزاء كأنه قيل إن تدع ربك بأن يخرج لنا يخرج لنا ، وهذا بتنزيل سبب السبب منزلة السبب. وقوله :"قال أتستبدلون الذي هو أدنى بالذي هو خير" هو توبيخ شديد فقد تلقى موسى لقسي - عليه السلام - طلبهم بالاستنكار " وفي الاستبدال للخير بالأدنى النداء بنهاية حماقتهم وسوء اختيارهم". (Ibn 'Āšūr, 1984:1/314) وقوله : اهبطوا مصرا فإن لكم ما سألتم " 
Abdelrahman Moawad Ali Tahawi

إما بمعنى أن ما يطلبونه هين زهيد، لا يستحق الدعاء فهو موفور في أي مصر من الأمصار، فاهبطوا أية مدينة فإنكم واجدوه فيها.. وإما بمعنى عودوا إذن إلى مصر التي أخرجتم منها.. عودوا إلى حياتكم الدارجة المألوفة. إلى حياتكم الخانعة الذليلة.. حيث تجدون العدس والبصل والثوم والقثاء! واتركوا الأمور الكبار التي ندبتم لها.. ويكون هذا من موسى - عليه السلام - تأنيبا لهم وتوبيخا، والباحث يرجح هذا التأويل الذي استبعده بعض المفسرين، وسبب الترجيح ما أعقبه في السياق من قوله تعالى: وضربت عليهم الذلة والمسكنة وباءوا بغضب من الله " فإن ضرب الذلة والمسكنة عليهم، وعودتهم بغضب الله، لم يكن - من الناحية التاريخية - في هذه المرحلة من تاريخهم; إنما كان فيما بعد، بعد وقوع ما ذكرته الآية في ختامها. (El-Messiri, 2021:3/352)

وقوله فإن لكم ما سألتم الظاهر أن الفاء للتعقيب عطفت جملة إن لكم ما سألتم على جملة اهبطوا للدلالة على حصول سؤلهم بمجرد هبوطهم مصر وأشار بعض المفسرين إلى أن الواو هنا تفيد التعليل (2) 2.

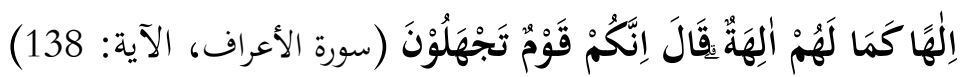
وردت هذه الآية في سياق عرض قصة بعث موسى -عليه السلام - إلى فرعون وملئه وكيف نصره الله عليهم. وجاءت هذه الآية تعرض طبيعة بني إسرائيل والتي فسدت نفوسهم، والتوت فطرتهم بعد أن عاشوا حياة الذل والسخرة والمطاردة والطغيان. "وَجَاوَزْنَا بِبنَيْ إسْرَآعِيْلَ الْبَحْرَ..." ، أي عبرنا بهم البحر والمجاوزة هي البعد عن المكان عقب المرور فيه،(Ibn ’Āšūr, 1984:9/79)، ويقال جاوز الوادي إذا قطعة وخلفه وراءه، وجاوز

2- ليست مفيدة للتعليل إذ ليس الأمر بالهبوط بمحتاج إلى التعليل بمثل مضمون هذه الجملة لظهور المقصود من قوله اهبطوا مصرا ولأنه ليس بمقام ترغيب في هذا الهبوط حتى يشجع المأمور بتعليل الأمر. انظر التحرير والتنوير 345/1 
Abdelrahman Moawad Ali Tahawi

بغيره، عبر به، وقرئ "جوزنا" بمعنى: أجزنا. يقال: أجاز المكان وجوزه بمعنى جازه.-Al)

Rāzī, 1985:14/232)

"فَاتَوْا عَلْى قَوْرٍ يَّْْكُفُوْنَ...."، أي مروا على قوم يتلازمون على عبادة أصنام لهمه،

فالعكوف هو المازمة بنية العبادة، قال الزجاج " أي يواظبون عليها ويلازمونها، يقال لكل من لزم شيئا وواظب عليه عَكَفَ - يَعْكِف و يعْكُف" (Az-Zujaj, 1988:2/371). وقد أتى بحرف الجر "على" ؛ لأنهم لم يقصدوا الإقامة في القوم، وإنما لقوهم في طريقهم، والإتيان بـ"أصنام" نكرة للتحقير من شأنها وأنها مجهولة. وفي وصف الأصنام بأنها لهم توبيخ لهم يقول ابن عرفة التونسي: "عادتهم يجيبون بأنه زيادة تشنيع لهم وتنبيه على جهلهم وغوايتهم في أنهم يعبدون ما هو ملك لهم فيجعلون مملوكهم إلهـم" (Ibn 'Āšūr, 1984:9/80).

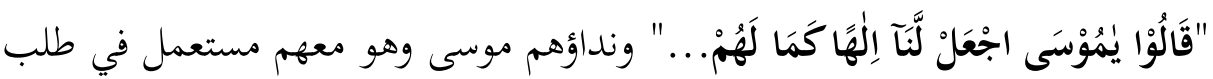
الإصغاء لما يقولونه، إظهارا لرغبتهم فيما سيطلبون، وسموا الصنم إلهاً لجهلهم فهم يحسبون أن اتخاذ الصنم يجدي صاحبه قال ابن عطية: "الظاهر أنهم استحسنوا ما رأوا فأرادوا أن يكون ذلك في شرع موسى وفي جملة ما يُنقرب له إلى الله وإلا فبعيد أن يقولوا لموسى اجعل لنا إلها نفرده بالعبادة" (Al-Andalusī, 1992:7/149).

وفي كلامهم هذا دلالة على انخلاعهم من التوحيد، وكشف عن طبيعتهم فهي طبيعة مخلخلة العزيمة، ضعيفة الروح، والتشبيه في قوله :" كَمَا لَهُهْ آلِهَةِّة" أرادوا به حض موسى على إجابة سؤالهم وابتهاجاً بما رأوا من حال القوم الذين مروا عليهم.

وقوله: "قَالَ إنَّكُمْ قَوْمُ تَجْهَلُوْنَ" هو جواب موسى على كلامهم، أي إنكم قوم تجهلون عظمة الله، وما يجب أن ينزه عنه من الشريك والنظير، ولم يقل موسى تجهلون ماذا ب ليكون في إطلاق اللفظ ما يفيد الجهل الكامل الشامل، كما فيه إشارة إلى أن الانحراف عن التوحيد إلى الشرك إنما ينشأ من الجهل والحماقة، وأن العلم والعقل يقود كلاهما إلى الله الواحد يقول الزمخشري: "تَعجّب من قولهم على أثثر ما رأوا من الآية العظمى والمعجزة الكبرى فوصفهم 
Abdelrahman Moawad Ali Tahawi

(Al-Zamaȟšrâī, "بالجهل المطلق وأكده، لأنه لا جهل أعظم مما رأى منهم ولا أشنع .2009:2/144)

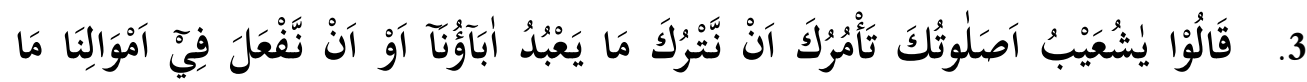

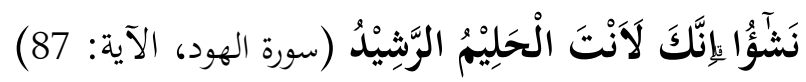

لما أمر شعيب - عليه السلام- قومه من أهل مدين بعبادة الله - تعالى - وترك عبادة الأوثان ، وبإيفاء الكيل والميزان ردوا عليه على سبيل السخرية والاستهزاء فقالوا: أصلاتك تدعوك لأن تأمرنا بترك عبادة الأصنام التي عبدها آباؤنا، وتأمرك بأن نترك تطفيف الكيل والميزان؟ فالخطاب هو خطاب تهكم وسخرية من نبيهم شعيب. قال الفخر الرازي:" اعْلَمْ أنَّ

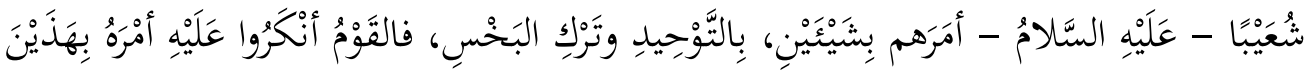

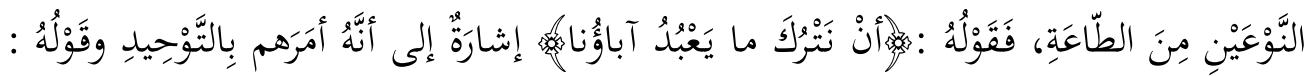

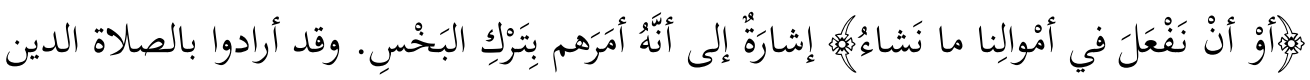
والمعنى: دينك يأمرك بذلك؟ وأطلق عليه الصلاة لأنها أظهر شعائر الدين، وروي أن شعيبا كان كثير الصالاة وكان قومه إذ رأوه يصلي تغامزوا وتضاحكوا"(Al-Rāzì, 1985:18/42). "إنَّكَكَ لَآنتَّ الْحَلْيْمُ الوَّشِيْدُ"، أي إنك لأنت العاقل المتصف بالحلم والرشد قال الطبري:" يستهزئون به فإنهم أعداء الله قالوا له ذلك استهزاءً ، وإنما سفّهوه وجهّلوه"-A1) (Tabarī, 1987:6/4408. وقال الألوسي: " وصفوه بهذين الوصفين الجليلين على طريقة الاستعارة التهكمية، فالمراد بهما ضد معناهما، وهذا هو المروي عن ابن عباس رضي الله عنهما، وإليه ذهب قتادة والمبرد"، وهناك من أشار إلى جواز بقاء هذين الوصفين على ظاهرهما؛ لأن شعيبا كان موصوفا عند قومه بالحلم والرشد، ولكن الأرجح هو ما ذهب إليه الطبري والألوسي ؛ لأنه الأنسب بالسياق قبله فهو تهكم أيضا(Al-Alūsī, 2008:7/161). 
Abdelrahman Moawad Ali Tahawi

وقد أكدوا قولهم بأكبر تأكيد حيث اشتملت الجملة على ثلاثة مؤكدات هي "إن" ، ولام القسم، وصيغة القصر.

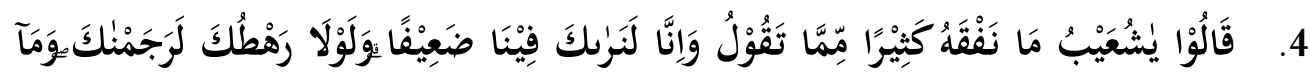

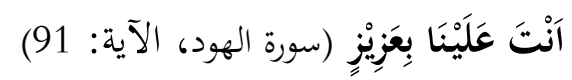

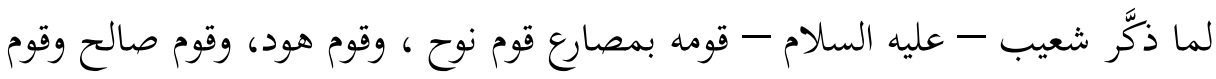

لوط وحذرهم من العناد والتكذيب والمخالفة وحثهم على الرجوع والاستغفار، جاء الرد منهم يحمل الاستهزاء بل والتحذير لشعيب -عليه السلام- .

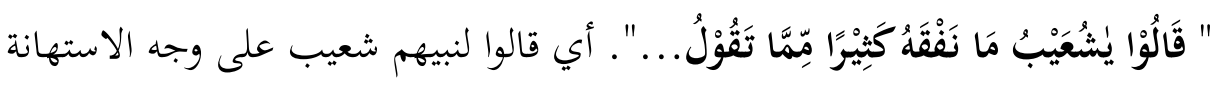

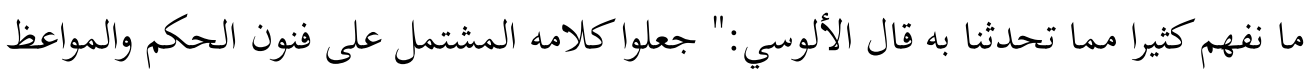

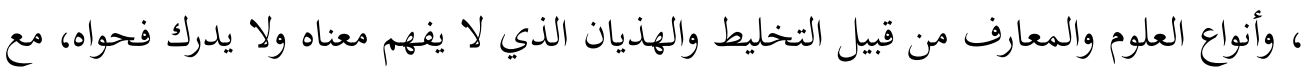
أنه كما ورد في الحديث الشريف (خطيب الأنبياء)" (Al-Alūsī, 2008:7/167). فالمراد من خطابهم هذا هو استهجان قول شعيب وهذا مقدمة لإدانته واستحقاقه الذم والعقاب عندهم.

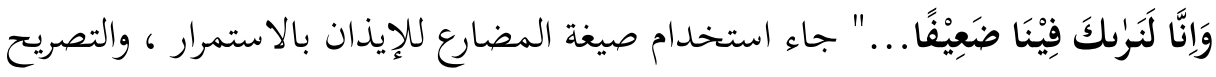

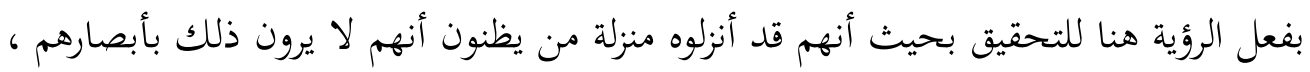

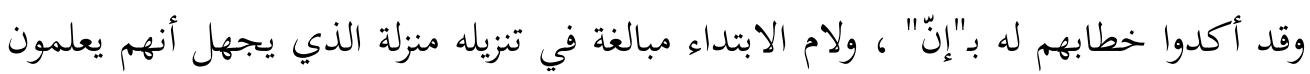
ذلك فيه ، وفي هذا التنزيل تعريض بالغباوة وقلة الفهم، ومن فساد التفسير تفسير قولهم:

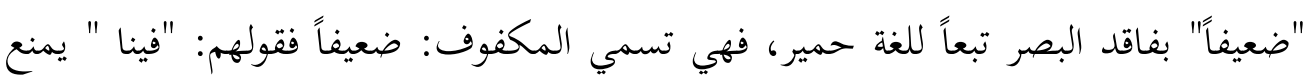
هذا التفسير. فالأعمى أعمى فيهم وفي غيرهم.

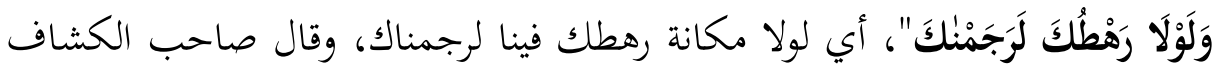

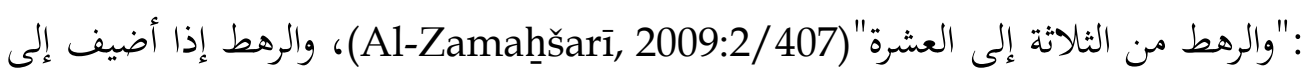

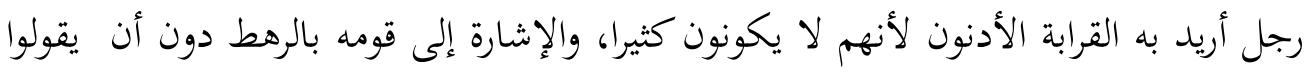


Abdelrahman Moawad Ali Tahawi

(Ibn 'Āšūr, قومك ؛ لأنهم كانوا أصحاب مكانة عندهم فقد كانوا من خاصة أهل دينهم .1984:12/149)

و الإتيان بحرف النفي قبل الضمير في قوله : "وَمَاَ أنْتَ عَلَيْنَا بِعَيٍٍِْ " للدلالة على أن

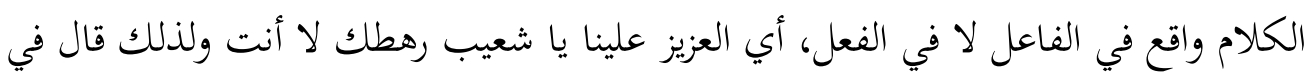

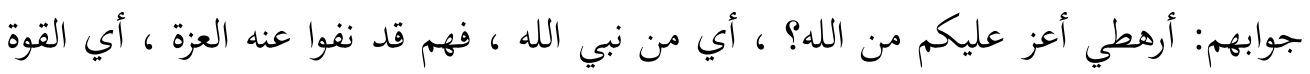

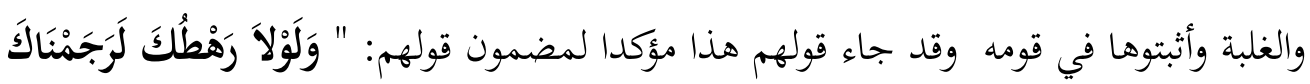

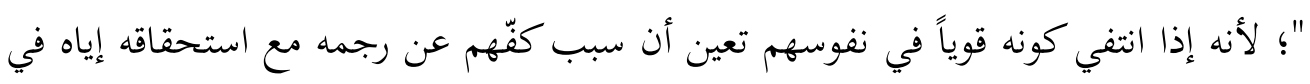
اعتقادهم هو إكرامهم لقومه لمكانتهم عندهم وقصدهم من هذا الكلام تحذيره من الاستمرار على مخالفة رهطه بأنهم يوشك أن يخلفوه وييحوا لهم رجمه.

\section{الخلاصة}

يتجلى لنا بعد هذه التطوافة مع آيات نداء الأعلام في القرآن الكريم أن النداء بالعلمية

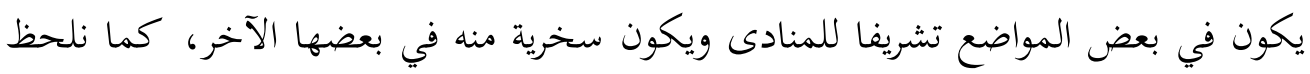

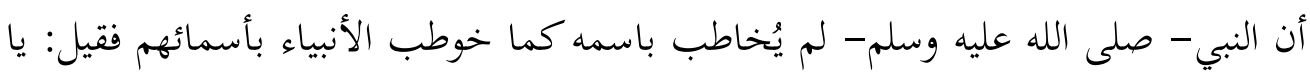

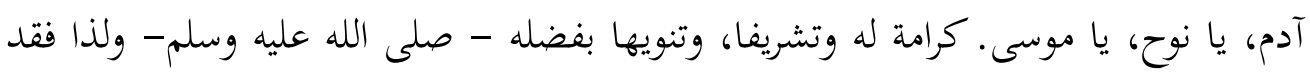

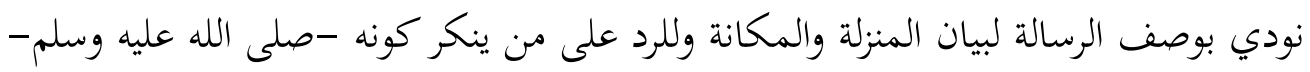
مرسلا بشرع من الله -عز وجل- وللأمر بتوصيل أمانة السماء إلى من أرسل إليهم .وكذلك الكنانك

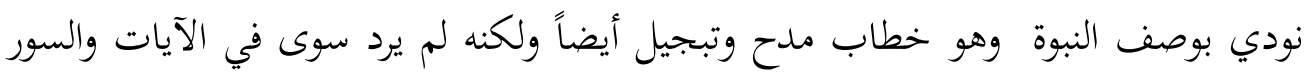

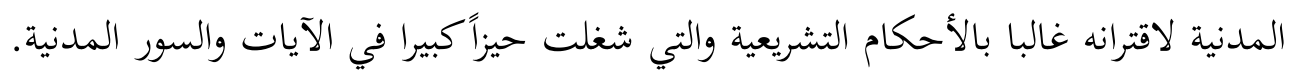

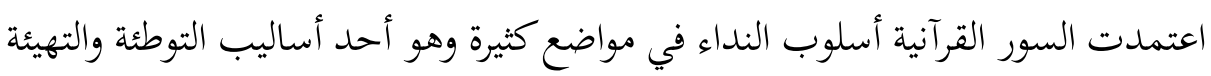

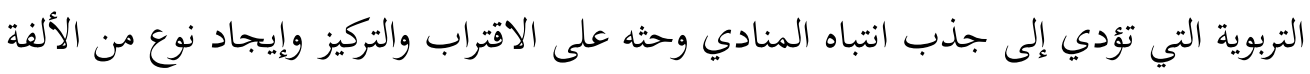


والاستمالة والخصوصية التي تشعره بمدى أهميته واهتمام الخطاب القرآني به يجعله أكثر

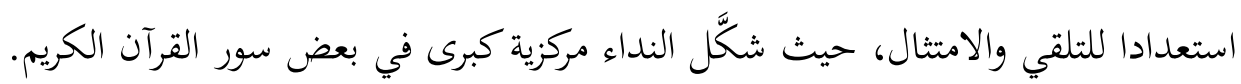
المتأمل في النظم القرآني يلحظ كثرة ورود الأساليب الإنشائية من أمر ونهي واستفهام مقترنة مع النداء القرآني وكثيراً ما يكون ورودها في النص الكريم مصحوبا بتحول دلالي تفارق

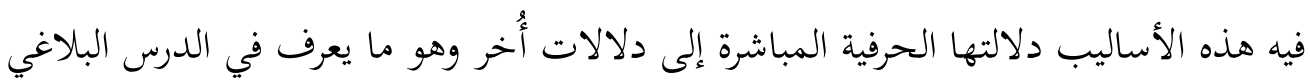
القديم بفكرة الأغراض. وهذا التحول من الدلالة الحرفية المباشرة إلى الدلالة البلاغية ينطوي على قدرة لافتة تسهم في جذب انتباه المتلقي وبقاء تواصله مع النص في أكثر حالاته تجاوبا وتفاعلا.

\section{المصادر والمراجع}

Abū Ḥayyān Al-Taūḥ̣ īdī. (1983). al-Baḥ r al-Muḥ ịṭ (3, Ed.). Beirut: Dar al- Fikr.

Al-Alūsī. (2008). Rūḥ al-Ma'ānī fì Tafsìr al-Qur'ān al-'Az ìm Wa al-Sab' al$M a^{\prime} a \bar{n} \bar{\imath}$ (Abū 'Abduraḥ man Fūad ibn Sirāğ Abdul-gafār, Ed.). Cairo: Al-Tawfikiya Bookshop.

Al-Andalusī, I. 'Aț ìyä̈ . (1992). al-Muh arar al-Wağ iz Fì Tafsīr al-Kutub al-'Aziz (al-Mağlis al-'Ilmī bi Taroudant, Ed.). Cairo: Maktabä̈ Ibn Taìmìyaï.

Al-Baqā'ī. (1984). Naẓm al-Durar Fì Tanāsub al-Ayāt wa al-Suar. Cairo: Dār al-Kitāb al-Islāmī.

Al-Kalabī, I. Ğazī. (1995). al-Tashīl li 'Ulūm al-Tanzīl. Beirut: Dar AlKotob Al-ilmiyah.

Al-Qurțubī. (2006). Tafsīr al-Qurțubì Al-Ǧāmi' li Aḥkām al-Qur'ān. Beirut: Muassasä̈ al-Risālä̈.

Al-Rāzī, F. (1985). Mafātīh Al-Ġaỉb (3rd ed.). Beirut: Dar Al-Fikr.

Al-Ṣābūnī, M. A. (1997). Ṣafwä̈ al-Tafāsīr. Cairo: Dār Al-Ṣābūnī.

Al-Sakākī, Y. bin A. B. (1987). Mitftāḥ al-'Ulūm (N. Zaruzūr, Ed.). Beirut: Dar Al-Kotob Al-ilmiyah. 
Al-Ṭabarī, M. I. Ğarīr. (1987). Ğāmi' Al-Bayān F̄̄ Tafsìr Al-Qurān. Cairo: Dār Al-Hadīt.

Al-Zamahšarī. (1995). Tafsīr Al-Kaššăf 'An Haqā'iq Al-Tanzìl Wa Ü'yūn Al-Aqāwyil Fì Wuğūh Al-Ta awyl (1st ed.; M. A. Bīḍūn, Ed.). Beirut: Dar Kutub al-Ilmiyah.

Al-Zamahš̌arī. (2009). Tafsìr Al-Kaššāe 'An Haqā'iq Al-Tanzīl Wa Ū'yūn Al-Aqāwyyil Fì Wuğūh Al-Ta awwyl. Beirut: Dar Marefah.

Al-Zuğāāīi, A. bin I. (1985). Kitāb al-Lāmāt (M. Al-Mubārak, Ed.). Damascus: Dar al- Fikr.

Az-Zujaj, A. I. (1988). Ma'ānī al-Qur'ān wa I'rābuhu (A. A. Šiblī, Ed.). Beirut: Alam al-Kutub.

El-Messiri, A. W. (2021). Mausūa'ä̈ al-Yahūdi Wa al-Yahūdiyä̈ Wa alSahyūnìyyä̈. Cairo: Dār Al-Šurūq.

Ibn 'Āšūr. (1984). Tafsīr al-Taḥīr wa al-Tanwiyr. Tunis: Dar Sahnoon.

Ibn Al-Ğauzī, A. (2002). Zād al-Masìr fì 'Ilm al-Tafsìr. Oman: Dar Ibn Hazam.

Ibn Al-Turkmānī. (2020). Bahğä̈ Al-'Arīb F̄̄ Bayān Mā Fì Kitābillah Al'Azīz Minn Al-Ġarīb (M. A. Ibrāhīm, Ed.). Cairo: Al-Haiyah AlMisriyah Al-'Âmah Li-al-Kitâb.

Ibn Katīir. (2002). Tafsìr al-Qur'ān al-'Ażìm (1st ed.). Cairo: Maktabä̈ AlȘafā.

Imām Al-Buhāāī. (1990). Șaḥịh Al-Buḥārī (Al-Mağlis Al-'Ala Li Šuūn AlIslāmīyä̈, Ed.). Cairo.

Murād, M. S. M. (2004). Asālìb al-Nidā' fi al-Qur'ān al-Karìm. Ain Shams University.

Sulayman, M. ibn. (1994). Al-Ašbāh wa al-Naẓāir (A. Šahāätä, Ed.). Cairo: al-Haīä̈ al-Miṣrīä̈ al-'āmä̈ Lilkitāb. 